Abstract

\title{
Dealing with Ethical Issues in Countering Violent Extremism (CVE): An Exploration of Concepts and Tools to Support CVE Programs and Practitioners ${ }^{\dagger}$
}

\author{
Michael Kowalski (D)
}

check for

updates

Citation: Kowalski, M. Dealing with Ethical Issues in Countering Violent Extremism (CVE): An Exploration of Concepts and Tools to Support CVE Programs and Practitioners.

Proceedings 2021, 77, 2.

https://doi.org/10.3390/

proceedings 2021077002

Published: 23 April 2021

Publisher's Note: MDPI stays neutral with regard to jurisdictional claims in published maps and institutional affiliations.

Copyright: (c) 2021 by the author. Licensee MDPI, Basel, Switzerland. This article is an open access article distributed under the terms and conditions of the Creative Commons Attribution (CC BY) license (https:/ / creativecommons.org/licenses/by/ $4.0 /)$.
Head of Expertise and Quality Center, Netherlands Inspectorate for Justice and Security, P.O. Box 20301, 2500 EH The Hague, The Netherlands; m.kowalski@inspectie-jenv.nl

† Presented at the Global Safety Evaluation Workshop, Online, 1 July-31 December 2020.

Abstract: Countering violent extremism (CVE) implies many pressing ethical issues. For policymakers and professionals, it is essential to identify concrete ethical dilemmas and to understand the underlying more abstract ethical issues. The proposed typology of ethical issues consists of four different levels: the structural, the political, the professional, and the personal levels. Ethical issues on the structural level are rooted in the conditions of the world risk society, such as the morality of CVE and counterterrorism in general or its fundamental inconsistencies. On the political level, the phenomenon of the state of emergency, the politicization of CVE and counterterrorism, the legitimacy of state interventions, and the tension between secrecy and transparency all play a role. Professional values can conflict with organizational interests on the professional level. Finally, on the personal level, integrity can come under pressure due to conflicting values. An exploration of the benefits for counterterrorism practitioners of the consequentialist, deontological, and virtue-ethical approaches concludes that none of them offers a sound approach to the practice of counterterrorism in a liquid world risk society. This provides an opportunity to highlight the potential of the philosophical concept of "compromise" (Benjamin) in reconciling opposing principles and underlying values of the key ethical approaches. A major source of guidance and inspiration for compromise is phronesis, or practical wisdom. Another powerful concept is the ethics triangle (Svara). This ethics triangle implies that public administrators should strive towards a balance of virtue, principle, and good consequences, all seen from the perspective of the duty of the public interest. There are several ethics tools available that can inform the design of CVE programs and support dealing with the various types of ethical issues once a CVE program is started. First, it is useful to engage in a closer analysis and value clarification of the ethical issues at stake. Second, the already established tool of privacy impact assessment represents an inspirational point of departure for a broader ethics impact assessment. Third, the institutionalization of ethics support in the field of CVE can be realized by the establishment of ethics committees, the appointment of ethics advisors or ethics rapporteurs, or the installation of reflection groups. Fourth, the implementation of tools of ethics support like moral case deliberation can empower CVE professionals to deal with ethical issues. It can also improve their decision making, support collective learning, and contribute to the development of policies and guidelines in the field of CVE and counterterrorism. Last, but not least, evaluating CVE programs can benefit from taking ethical issues into account. Moving beyond mandatory rituals of ethics checks can lead to an in-depth engagement with professionals and stakeholders within CVE programs and a re-adjustment and fine-tuning of programs if necessary. In the long run, the integration of ethics into the design, implementation, and evaluation of CVE programs can strengthen the legitimacy of these programs among targeted communities, professionals, and societies at large.

Keywords: counterterrorism; countering violent extremism; ethics; ethics support; evaluation 